\title{
EDUCACIÓN Y TRANSFORMACIÓN SOCIAL: EL PROYECTO EDUCATIVO PARA LAS MUJERES EN EL IMAGINARIO ANARQUISTA
}

\author{
Teresa González Pérez
}

Universidad de La Laguna, España

\begin{abstract}
$\cos 80$
\section{EDUCAÇÃO E TRANSFORMAÇÃO SOCIAL: O PROJETO EDUCACIONAL PARA AS MULHERES NA IDEOLOGIA ANARQUISTA}

\begin{abstract}
Resumo
Ao longo da história, o movimento operário tomou várias medidas para melhorar o nível educacional de seus integrantes. Tanto socialistas, quanto anarquistas, se converteram em agentes educadores e criaram instrumentos próprios de educação e cultura para os seus membros. O programa alternativo dos anarquistas para os setores populares se refletiu nas escolas noturnas e dominicais, conferências, palestras, cursos e leituras. Esses espaços, além de servirem para instrução, também foram usados para propagar o ideário de emancipação. Nesse artigo, analisa-se a educação das mulheres no projeto de transformação social da ideologia anarquista. O objetivo principal é a análise das alternativas de formação defendidas pelos anarquistas espanhóis para as mulheres, entre a segunda metade do século 19 e o primeiro terço do século 20. Constatou-se que as mulheres foram integradas nos grupos anarquistas e a sua educação, em termos discursivos, se constituiu numa luta constante. Desde o século 19 defendiase a igualdade e, em sua trajetória, desenvolveram-se várias medidas para esse fim. A emancipação da sociedade devia afetar os âmbitos públicos e privados, em uma sociade antiautoritária e antihierárquica. No entanto, apesar das suas abordagens avançadas, esses grupos não se desprenderam dos estereótipos, nem se rompeu com o modelo tradicional e com crenças discriminatórias da época.

Palavras-chave: Espanha, movimento operário anarquista, mulheres, educação integral, revolução social, emancipação, igualdade.
\end{abstract}

\section{EDUCATION AND SOCIAL TRANSFORMATION: THE EDUCATIONAL PROJECT FOR WOMEN IN THE ANARCHIST IDEOLOGY}

\section{Abstract}

The working movement has taken several educational actions through history in order to improve its status condition. Socialists as well as anarchists became the main educational entity and they created their proper educational and cultural tools for their militants. The alternative programme of the anarchists for the popular sectors was visible in classes by night or on Sundays as well in conferences, talks, courses and lectures. Apart from taking into account instruction they also 
divulged their emancipating ideology. In this article we try to study women education concerning the social transformation in this anarchist ideology. The main objective is to analyze the alternative of training which the anarchists defended for Spanish women in the second half of the 19 century and in the beginning of the 20 century. So we have proved that women were integrated in anarchist groups and in their discourse education was a constant in their fight. Since the 19 century on they wanted equality and on their path they taken different kinds of action towards this goal. Their emancipation affected both the public and the private sectors, in an anti authoritarian and anti hierarchic society. Nevertheless, despite the advanced planning this emancipation did not get rid of stereotypes and it did not break off with the traditional model and the discriminatory tendencies of the time.

Key-words: Spain, working movement, anarchism, women, integral education, social revolution, emancipation, equality

\section{EDUCACIÓN Y TRANSFORMACIÓN SOCIAL: EL PROYECTO EDUCATIVO PARA LAS MUJERES EN EL IMAGINARIO ANARQUISTA}

\section{Resumen}

A lo largo de la historia el movimiento obrero ha emprendido diversas acciones educativas para mejorar su condición social. Tanto socialistas como anarquistas se convirtieron en el principal agente educador y crearon instrumentos propios de educación y cultura para sus militantes. El programa alternativo de los anarquistas para los sectores populares se plasmó en escuelas nocturnas y dominicales, conferencias, charlas, cursos y lecturas. Además de atender a la instrucción también difundieron su ideario emancipador. En este artículo pretendemos estudiar la educación de las mujeres en el proyecto de transformación social presente en el ideario anarquista. El principal objetivo se centra en analizar las alternativas de formación que defendían los anarquistas para las mujeres españolas entre la segunda mitad del siglo 19 y el primer tercio del siglo 20 . De los resultados obtenidos constatamos que las mujeres se hallaban integradas en los grupos ácratas y en su discurso la educación fue una constante en su lucha. Desde el siglo 19 planteaban la igualdad y en su trayectoria desarrollaron diversas acciones encaminadas a tal fin. La emancipación afectaba al ámbito público y privado, en una sociedad antiautoritaria y antijerárquica. No obstante, pese a sus avanzados planteamientos no se desprendió de los estereotipos ni rompió con el modelo tradicional y las creencias discriminatorias de la época.

Palabras-clave: España, movimiento obrero, anarquismo, mujeres, educación integral, revolución social, emancipación, igualdad.

\section{L'EDUCATION ET DE TRANSFORMATION SOCIALE: LE PROJET EDUCATIF POUR LES FEMMES DANS L'IDEOLOGIE ANARCHISTE}

\section{Résume}

Tout au long de l'histoire du mouvement ouvrier a pris diverses mesures pour améliorer leur niveau d'éducation. Les deux socialistes et anarchistes est devenu le principal agent éducateur et aux instruments créés de l'éducation et la culture de leurs membres. Le programme de remplacement des anarchistes pour les secteurs populaires se reflète dans les écoles du soir et le dimanche, conférences, cours, stages et conférences. En plus de servir la déclaration aussi propager leur idéologie de l'émancipation. Dans cet article, nous analysons l'éducation des femmes dans ce projet de transformation sociale à l'idéologie anarchiste. L'objectif principal est d'explorer diverses options pour la défense de la formation pour les femmes anarchistes espagnols entre la seconde moitié du $19 \mathrm{e}$ siècle et le premier tiers du $20 \mathrm{e}$ siècle. D'après les résultats, nous constatons que les femmes ont été intégrés dans les groupes anarchistes et l'éducation dans son discours a été une lutte constante. Depuis le 19e siècle a soulevé l'égalité et de sa carrière au point diverses mesures à cette fin. L'émancipation de la société touchées publics et privés, anti-autoritaire et anti-hiérarchique. Toutefois, en dépit de ses approches avancées n'est pas hors des stéréotypes et des a rompu avec le modèle traditionnel et des croyances discriminatoires de l'époque.

Mots-clé: L'Espagne, le mouvement ouvrier, l'anarchisme, les femmes, l'éducation intégrale, la révolution sociale, l'émancipation, l'égalité. 


\section{Introducción}

I movimiento obrero español desde sus orígenes consideró la educación
popular como un elemento destacado en su estrategia política y sindical. Las
primeras acciones educativas se localizaron hacia la mitad del siglo 19, aunque fue a partir de 1868, sexenio Democráticos cuando elaboraron su primer programa político-pedagógico de influencia bakunista. Estas primeras iniciativas evolucionaron durante la Restauración hacia dos modelos educativos diferenciados, desarrollados respectivamente por socialistas y anarquistas, si bien manteniendo ciertos puntos en común. Ambos confluyeron en trazar un modelo educativo para los sectores populares. Promovieron escuelas nocturnas y dominicales, conferencias, charlas, cursos, bibliotecas y publicaciones que contribuyeron a la educación de las clases populares, incluso impulsaron actividades a favor de la educación bajo el influjo de iniciativas europeas. De este modo, las organizaciones obreras se convirtieron en el principal agente educador, crearon instrumentos propios de educación y cultura para sus militantes y, a la vez, subsanaron las deficiencias de la educación oficial.

Todas las innovaciones conformaron una etapa álgida en la pedagogía española, producto de la circulación de nuevas ideas transferidas por los europeos, junto a la confluencia entre algunos planteamientos institucionistas y regeneracionistas. En este sentido el anarquismo, introducido en España desde la segunda mitad del siglo 19 adquirió mayor fuerza en las primeras décadas del siglo 20, incidió en la importancia de la educación para la clase obrera, amparado en la idea de renovación social a través de la educación integral. Siguiendo esa línea en el primer tercio del siglo 20 español hubo distintas iniciativas educativas que, desde la óptica de la renovación pedagógica, planteaban alternativas a las escasas escuelas públicas y a sus caducados métodos de enseñanza.

La escuela moderna de Ferrer i Guardia inspirada en la obra de Paul Robin, Orfelinato Prévost en Cempuis - Francia, y fundamentada en los principios racionales tenía entre sus objetivos la coeducación. Ferrer partía de la igualdad sexual y en su programa educativo destacaba la importancia de que los niños y las niñas recibieran una enseñanza idéntica. Los anarquistas asumieron la pedagogía ferreriana y siguiendo su metodología instaron a la creación de escuelas racionalistas en los sindicatos, sociedades y centros obreros a las que incorporaban a las mujeres.

En opinión de algunos expertos el anarquismo en España adquirió más arraigo y mayor base popular que en el resto del mundo. Si bien prendió en uno de los países pobres y atrasados de Europa fue en Cataluña, región tradicionalmente próspera y la más avanzada de España, donde primero se constituyeron grupos anarquistas y donde las ideas libertarias adquirieron mayor prestigio. No obstante, otro núcleo destacado se localizó en Andalucía, una zona deprimida, donde tuvo un fuerte arraigo entre el campesinado.

Desde estos lugares proyectó su difusión a otras zonas del estado y mantuvo un compromiso activo con la sociedad. Algunos autores refieren que en España ha existido una larga tradición libertaria. En realidad el anarquismo no se halla relacionado con el estado de atraso ni de miseria de los pueblos. Se trata de una toma de conciencia individual que impactó en las personas de diversa procedencia, preocupadas por el problema de la justicia, de la desigualdad y de la felicidad. En este caso caló en el 
campesino iletrado, en el obrero rebelde, en el intelectual o el aristócrata inquieto, pero las circunstancias históricas de España truncaron las perspectivas ácratas.

Nuestro propósito es conocer la educación de las mujeres en el proyecto de transformación social que difundió el imaginario ácrata. El principal objetivo está centrado en analizar las alternativas pedagógicas que defendían los anarquistas para las mujeres españolas entre la segunda mitad del siglo 19 y el primer tercio del siglo 20. Contamos para ello con la información suministrada por fuentes de diverso tipo, tanto bibliográficas como hemerográficas. Entre los diversos documentos manejados se hallan libros, revistas, boletines y programas escolares.

De igual manera se han consultado aquellas obras generales que revisten interés para el tema estudiado. Reconocemos ciertas limitaciones para el desarrollo de la investigación, sobre todo, en lo concerniente a las fuentes y a la metodología. Tampoco ignoramos nuestros límites de carácter epistemológico y de interpretación hermenéutica, así como de nuestras posibilidades de conocimiento. Es evidente, por otra parte, que cualquier tema que se enfoque desde la perspectiva histórica aparecen interrelacionados diversos factores, porque toda realidad presente o pasada es compleja. El método de análisis ha prestado atención a la perspectiva de las mujeres, pero guiado por la preocupación de una serie de cuestiones tales como el análisis de la representación de categorías ideológicas, la relación con el imaginario social y la función de los discursos dominantes.

\section{Propuestas y programa de acción de los anarquistas en España}

Desde finales del siglo 19 se sucedieron en España diversas iniciativas sobre educación popular. Tenemos constancia de la existencia de tres agentes principales comprometidos con la educación de la clase obrera. A saber la burguesía reformista con distintos presupuestos teóricos apoyados en la ILE, actividades de extensión universitaria y la universidad popular, las asociaciones católicas y el movimiento obrero. Al margen de lo anterior destacar las formulaciones de las propias organizaciones obreras donde los trabajadores concedían un papel clave a la educación "dentro de su estrategia política" (Tiana, 1994, p. 601).

Las ideas anarquistas se introdujeron en España en la primera mitad del siglo 19, sus postulados circularon en distintos foros de debate y discusión. Desde fecha temprana se difundieron ideas sobre la formación intelectual y manual de la clase trabajadora principalmente en áreas de Madrid, Cataluña y Andalucía. A través de diversos centros culturales - ateneos, casinos - desplegaron sus propuestas y las hicieron realidad. En este sentido se crearon centros docentes y cívico-culturales acordes con sus principios ideológicos, como la Escuela del Trabajador (Madrid, 1845), el Fomento de las Artes también conocido como Velada de los Artistas (Madrid, 1847) y el Ateneo Catalán de la Clase Obrera (Barcelona, 1861).

Además de instruir en contenidos culturales fueron foros activos de discusión, ensayaron una nueva conciencia política-pedagógica como modelo de formación del nuevo ciudadano. La alternativa didáctica despertó recelos en las autoridades y en ocasiones hubo dificultades para desarrollar su labor porque los dirigentes de estos locales y principales animadores fueron perseguidos. En la segunda mitad de la centuria adquirieron mayor fuerza incidiendo en la importancia de la educación para la clase obrera, amparados en la idea de renovación social a través de la educación integral. Tarea que consideraban 
fundamental para conseguir la revolución, porque la lucha obrera se identificaba con la lucha por la cultura y la educación (Tiana, 1983).

De esta manera educación y cultura se convirtieron en instrumentos trascendentales en la liberación de la clase trabajadora y fueron una constante en sus reivindicaciones. Con una base racionalista y científica se convirtieron en el credo de los obreros y formaron parte de su ideología (Luis, 1994). Así promovieron escuelas nocturnas y dominicales, conferencias, charlas, cursos, bibliotecas y publicaciones que contribuyeron a la educación de las clases populares (Guereña, 2006).

La necesidad de alternativas a la educación oficial originó que las organizaciones obreras se convirtieran en el principal agente educador, creando instrumentos propios de educación y cultura para sus militantes (Tiana, 2003). Se encargaron de subvencionar proyectos educativos, aferrados a la fe pedagógica, empeñados en combatir el analfabetismo y superarse a través de la educación científica y antiautoritaria (Ackelsberg, 1999). Rechazaban la educación oficial por domesticadora, clerical, autoritaria, perpetuadora del régimen dominante y marginadora de las clases trabajadoras $\mathrm{y}$, además, porque contribuía a su desescolarización y analfabetismo (Tiana, 1983). El objetivo consistía en ampliar la base cultural y extender la alfabetización a todos los sectores sociales, abarcando especialmente a las mujeres que ostentaban los mayores índices de analfabetismo (Ackelsberg, 1999).

Bajo el influjo de iniciativas europeas plantearon una educación alternativa y revolucionaria, desvinculada de la educación oficial, alimentados de las tesis que circulaban por diferentes foros. Los anarquistas recogieron los postulados de Proudhon, Robin, Kropotkin y Bakunin. La tradición de los mentados autores fue punto de referencia para Ferrer i Guardia, figura mítica que consagró el modelo educativo para los anarquistas españoles (Tiana, 1994). No en vano las propuestas educativas desarrolladas por el movimiento anarcosindicalista español constituyen una de las experiencias más importantes a nivel mundial (Guereña, 2006).

El anarquismo impregnado de una mentalidad pedagógica consideró que la educación era la tarea fundamental de la revolución (Luis, 1994). Así en multiplicidad de citas y referencias hacian hincapié en el problema de cultura y la necesidad de su conquista ${ }^{1}$, requisito previo a la revolución "¿cómo de la nada del analfabetismo y la incultura podía brotar algo?” (Lorenzo, s.f, p. 86) ${ }^{2}$, subrayando que la educación y la cultura eran instrumentos de liberación para la masa obrera. Las mujeres y los niños formaban parte de la "muchedumbre ignorante" y a todos esos desheredados había que redimirlos a través de las letras (Litvak, 2001, p. 101).

En las primeras décadas del siglo 20 el anarquismo fortaleció la idea de educación para la clase obrera. Proponían una enseñanza racionalista y laica, no competitiva y, sobre todo, no sexista. La expansión de las actividades educativas fue una realidad que se plasmó en la creación de escuelas racionalistas y centros culturales. La educación apareció como

\footnotetext{
${ }^{1}$ En 1913 Ricardo Mella escribía: "¿Quién duda de la imprescindible necesidad de cultura en que vivimos? ¿Quién duda de la eficacia de una labor intensamente cultural que sacudiera la pereza de las inteligencias" (Mella, 1979, p. 86).

2 Anselmo Lorenzo no dudó ni un ápice en afirmar que "Si la burguesía realizó su revolución fue gracias a la Enciclopedia. Si el proletariado debe hacer triunfar la suya, no será debido solamente a su combatividad "atávica" sino también, y más profundamente, a la extensión de la obra cultural de creación de escuelas y ateneos y federaciones de ateneos en acción mancomunada" (Lorenzo, s/f).
} 
una constante desde comienzos de la centuria en los diferentes congresos celebrados por los anarquistas en España. La educación libertaria para conseguir la emancipación fue una expresión presente en los tres Congresos celebrados en las dos primeras décadas: 1910, 1918 y 1919. Sin embargo los cambios políticos de la España monárquica afectaron sobre manera la evolución de las organizaciones anarquistas. La represión desatada con la dictadura de Primo de Rivera frenó su expansión y a pesar de que muchos centros fueron clausurados mantuvo abiertas algunas escuelas y ateneos (Tiana, 1994).

La experiencia anarquista cristalizó en un proyecto pedagógico de "instrucción integral". Una propuesta que alcanzó difusión notoria y en cuyo debate se incluía además de los obreros a los niños y las mujeres. La educación que pretendía infundir tenía como mira el desarrollo cultural de las mujeres, en cuanto que su participación activa era fundamental para la construcción de la nueva sociedad. En base a ello defendían su escolarización y sus derechos, así como mejorar su formación y elevar su nivel cultural. Además su educación era imprescindible para lograr la transformación de la sociedad pues, desde las tribunas anarquistas, se defendía el prototipo de mujer instruida, descartando la idea de que la ignorancia, la domesticidad y docilidad eran tributos femeninos loables.

Necesariamente para emancipar a las mujeres había que educarlas y, por otra parte, no era posible la reforma social si no se les instruía, máxime si era la primera maestra de sus hijos dada la influencia decisiva que ejercía sobre su educación (Espigado, 2002; Tavera, 2002). En este sentido organizaron conferencias, charlas, cursos, festivales y actividades diversas para mejorar su formación a la vez que atendían la enseñanza de niños y adultos. Junto a las escuelas y centros culturales las publicaciones alternativas desplegaban otros esquemas formativos. Entre ellas destacaban los periódicos libertarios como Solidaridad Obrera, Tierra y Libertad, CNT, entre otros, y las revistas Tiempos Nuevos, La Revista Blanca (Barcelona), Natura (Barcelona), Estudios (Valencia) que presentaban otras perspectivas frente a los patrones existentes. Recurrieron igualmente a la literatura anarquista española escrita por significados teóricos, tales como las obras de Anselmo Lorenzo, Federico Urales, López Montenegro, entre otros (Luis, 1994).

La producción literaria recogió la problemática femenina abordando la prostitución, explotación, abusos, miseria, analfabetismo... Pero el tema más abundante en la narrativa libertaria era la mujer deshonrada y abandonada por el burgués en su propio lugar de trabajo: la oficina del patrono, la fábrica, el taller o el campo. Como escribió Lily Litvak "un lugar donde el hombre, socialmente poderoso, ataca a la mujer proletaria, socialmente indefensa" (Litvak, 2001, p. 123). Es decir en aquellos espacios donde los hombres ostentaban la primacía. Igualmente, en los argumentos del cuento anarquista las mujeres forman parte de la temática recurrente con objetivo didáctico-ideológico (Litvak, 2003). Al modo de fervientes feministas los escritores no ignoraron a las mujeres caídas, deshonradas, seducidas, violadas, penosos episodios que utilizaba la cuentística con una significación social y con clara intención pedagógica ${ }^{3}$. Tanto a través de la educación informal como de la no formal trataron de ilustrar a hombres y mujeres, un proyecto educativo alternativo.

\section{Alternativas para la educación de las mujeres}

\footnotetext{
${ }^{3}$ Según escribe Litvak (2003, p. 35-39) porque: "El anarquismo apuntaba a la construcción de una moral, tanto en sus postulados teóricos como en el comportamiento cotidiano. [...] La educación libertaria empezaba desde temprano, desde la infancia".
} 
La educación a través de la historia se ha concebido como patrimonio exclusivo de la élite masculina. No obstante, la expansión de la instrucción pública, promovida por los estados liberales en el siglo 19, modificó el planteamiento educativo. Así se extendió la escolarización a las clases populares y se admitió la educación femenina, reconociéndose la necesidad de escolarización y culturización de las mujeres (Puelles, 1985). No obstante, la integración femenina en los sistemas educativos se ha realizado a partir de pautas educativas discriminatorias en función del sexo (Ballarín, 2001). Porque el eje de la instrucción de las mujeres era formarlas para que cumplieran mejor su tarea en el hogar: en el cuidado y atención a la familia y al marido, así como en la socialización de los hijos. Sin lugar a dudas la educación ha desempeñado un papel significativo en la configuración del rol social de las mujeres, pues en su proceso educativo han estado presentes las pautas ideológicas y culturales en torno a sus expectativas y proyectos de vida.

En el siglo 19 bajo gobierno liberal se inició la organización de la instrucción pública española. Sin embargo, no fue hasta mediados de ese siglo cuando asumió la educación femenina. La Ley de Instrucción Pública, promulgada en 1857, reconoció en su artículo 100 el derecho de las mujeres a recibir instrucción primaria. Por primera vez la legislación contemplaba este derecho a las mujeres al mismo tiempo que consideró la conveniencia de formar pedagógicamente a las maestras (Scanlon, 1987).

Pese a las modificaciones en las directrices educativas se acuñó un modelo escolar femenino subordinado y secundario con respecto al masculino. La sustitución de la tradicional segregación no significó un replanteamiento del sistema educativo desde la perspectiva de género, sino un reajuste que permitió un mecanismo más sutil de subordinación sexual. Si bien reconocía la importancia de la educación femenina ésta era inferior a la masculina y enfatizaba en las materias domésticas, a la vez que sancionaba toda actividad laboral que no fuera vinculada al hogar o al magisterio (Ballarín, 2001).

El modelo escolar se constituyó con la acuñación de una sociedad patriarcal, a sabiendas de que el acceso de las mujeres a la educación constituía una pieza fundamental para la mejora de su condición social. Tradicionalmente el objetivo de su instrucción atendía preferentemente a la institución familiar. Se orientaba a consolidar la formación de las mujeres en sus funciones de madre, hija y esposa; asimismo, se consolidaba, de manera indirecta, la división sexual del trabajo. Por esta causa se afirmaba que las niñas para no desarrollar un carácter varonil debían estudiar algunas asignaturas mujeriles (Caballero, $1883)^{4}$

En este marco se fomentaba la educación subordinada de las mujeres sustentada en asignaturas específicas. A través del currículum se transmitía la diferencia de género y se reforzaban los roles sexuales. Tanto en el contenido y la oferta de materias como en la inculcación de normas de conductas, los sistemas de valores y creencias eran inherentes al género y adecuados a la misión social a desempeñar (Jagoe, 1998) ${ }^{5}$. La enseñanza femenina tenía un fin utilitario no relacionado con el interés de las mujeres y hasta finales de

\footnotetext{
${ }^{4}$ Ponencia presentada por Fermín Caballero en 1869 en la Real Academia de Ciencias Morales y Políticas, donde censuró la memoria referida a la enseñanza mixta, defendida por M. Chadwich en la Academia de Ciencias Morales y Políticas de París (Caballero, 1883, p. 399-401).

${ }^{5}$ Catherine Jagoe afirma al respecto que "a las mujeres se les ofrecía siempre un programa diferente, enfatizando la inconveniencia moral de la coeducación y la necesidad de encauzar la enseñanza de manera que se institucionalizara la diferencia de género" (Jagoe, 1998, p. 107-108).
} 
la centuria decimonónica no se articuló la idea de que tenía derecho a educarse simplemente por sí misma. De forma general se repetía el rol sexuado:

Los pedagogos decimonónicos eran conscientes de que no se podía aislar el tema de la educación femenina de los corolarios con los que se vinculaba: el trabajo de la mujer y su función social en el estado burgués. Estaba claro entonces, como lo está hoy, que toda teoría educativa implicaba inevitablemente una visión de lo que debía ser el papel del individuo en la sociedad. (Jagoe, 1998, p. 132)

En 1870 el Congreso Obrero de Barcelona se pronunció a favor de la enseñanza integral, sustentada en las tesis de Bakunin, Fourier y Proudhon. Bakunin preconizaba derechos iguales para las mujeres porque era partidario de la completa emancipación de las mujeres y de su igualdad social con los hombres. Siguiendo sus planteamientos, en el segundo Congreso celebrado en 1872 en Zaragoza, Trinidad Soriano defendió la instrucción integral. Esta propuesta alcanzó notoria difusión y en su debate incluía a los obreros, los niños y las mujeres (Tiana, 1987, p. 97).

Trinidad Soriano, figura destacada de la Internacional y bakunista activo, participó en diversos encuentros internacionales pero a partir de 1880 desapareció de la escena, probablemente por discrepancias ideológicas ${ }^{6}$. Sin embargo, el conocido dictamen de Trinidad Soriano constituyó la base que sustentó todo el discurso educativo anarquista español y en el que se apoyó su defensa en años sucesivos. Las aspiraciones anarquistas eran de carácter igualitario. En sus argumentos emplearon como ejemplo de injusticia y desigualdad el papel otorgado socialmente a las mujeres y la situación femenina. Pero aún entre los propios ácratas ciertos sectores acentuaban las diferencias biológicas para sustentar el reparto de roles (Tocino, 2002). Se asumía con naturalidad las funciones desempeñadas por las mujeres en el ámbito privado y nadie, ni siquiera las propias anarquistas, tenía conciencia de la opresión doméstica de las mujeres (García, 1996).

La experiencia anarquista cristalizó en un proyecto pedagógico a pesar de la represión a la que fue sometida en su trayectoria. La propuesta de instrucción integral alcanzó difusión notoria incluyendo en su debate a las mujeres. En una época en la que se contabilizaban pocas escuelas oficiales los anarquistas proponían una enseñanza racionalista, laica, no competitiva y no sexista. Empeñados en su fe pedagógica subvencionaron proyectos educativos, defendieron la coeducación de los sexos e impulsaron la coeducación.

Pero como hemos indicado anteriormente la educación no quedaba reducida a la infancia ni se circunscribía a las instituciones escolares. Los esfuerzos ácratas no se redujeron a superarse a través de la educación científica y antiautoritaria. Además del aspecto escolar desplegaron una diversificada acción cultural y contaron con ateneos, bibliotecas y grupos artísticos. Insistieron una y otra vez en la necesidad de transformar la sociedad por medio de la educación alternativa y por ello incidían en formar a la mujer revolucionaria (Tiana, 1987).

\section{Secundar el modelo libertario para crear un nuevo orden}

\footnotetext{
${ }^{6}$ Trinidad Soriano, sevillano de origen, se inició en la democracia revolucionaria en sus años de estudiante en Barcelona. Participó en la Sección barcelonesa de la AIT (1868), en los congresos de La Haya, Barcelona (1870), Berna (1876), Verviers (1877) y formó parte de la CF en 1875, 1876, 1877 y 1879.
} 
Las mujeres españolas contaron con un espacio reconocido dentro del anarquismo (Espigado, 2002; Tavera, 2002) porque eran necesarias para la revolución pero para ello había que instruirlas. La desescolarización y el analfabetismo fueron dos de las grandes lacras que afectaban a la población femenina española. De ahí que el anarcosindicalismo se implicara de forma prioritaria en la lucha por la alfabetización y extensión cultural "como arma revolucionaria" (Tiana, 1987:155). Insistían en la necesidad de transformar a la sociedad a través de la educación alternativa para formar una mujer revolucionaria. Crear escuelas racionalistas y centros culturales propios para la formación y la rápida emancipación era una cuestión primordial. Este planteamiento fue expresión formal en los tres congresos de la CNT de 1910, 1918 y 1919.

Desde la creación de la Confederación Nacional del Trabajo (CNT) en 1910 -fuerza fundamental en el movimiento obrero español y central sindical orientada por el anarquismo- reconoció el derecho de las mujeres a su libertad económica y a un salario en igual cuantía que el de los hombres. Sin embargo planteó pocas iniciativas de lucha específica en relación a las mujeres, que apenas habían comenzado a asomarse al sindicalismo y tenían poca presencia en el mercado laboral. Hacia a fines de los años de 1920 y comienzos de la década de los 30 las mujeres formaron un grupo más notorio y se significaron en su actividad.

La represión de la dictadura de Miguel Primo de Rivera constituyó un freno a la expansión y muchos centros culturales cerraron. Sin embargo mantuvieron una actividad sostenida en las escuelas y los ateneos. El letargo se superó con la llegada de la II República, en su despertar fueron menos beligerante y más condescendiente con el nuevo gobierno. No obstante el gobierno republicano no atendió sus consignas, no resolvió sus demandas ni hubo cambios sustanciales, aunque en su imaginario anhelaban la revolución social. Ante tales circunstancias se desmarcaron y se trazaron una trayectoria de actuación independiente. De manera que no colaboraron con los gestores públicos como hicieron los socialistas (Tiana, 1994).

La educación que pretendía infundir el anarcosindicalismo tenía como mira el desarrollo cultural de las mujeres, en cuanto que su incorporación activa a la sociedad era fundamental para la construcción de un nuevo orden, y en base a ello defendían su derecho a escolarizarse. No obstante pese a que la liberación de las mujeres (Tocino, 2005) era una constante en su lucha no se puede referir a feminismo (Ballarín, 2001) desde la óptica del anarquismo hispano, porque ellas estaban presentes en sus reivindicaciones (Alvarez, 1976).

La emancipación afectaba al ámbito público y privado en una sociedad antiautoritaria y antijerárquica, pero consideraban que el feminismo estaba vinculado a la burguesía. Permeables a los discursos la liberación fue un tema polémico (Scanlon, 1986) que se mantuvo durante el primer tercio del siglo 20 , en la concreción de su programa insistían en la liberación, emancipación y redención conjunta de mujeres y hombres, imprescindible en la sociedad presente y no como demanda de futuro (López, 2003).

Hubo sectores importantes de la CNT que consideraron que la emancipación de la especie humana, globalmente entendida, pasaba por el fin de la dominación masculina. Apareció así la reivindicación de los aspectos específicos de la personalidad femenina, y de una educación adecuada para la mujer. (Tiana, 1987, p. 99) 
Al margen de la contaminación burguesa de algunos anarquistas la multiplicidad de discursos discriminatorios y de subordinación referidos a las mujeres no estaban incluidos en el discurso ideológico anarquista (López, 2003). Porque ellas figuraban como sujetos jurídicos activos y se les reconocía como personas con derechos (Lorenzo, 1974). Por esta causa había que emancipar a las mujeres, liberarlas de las viejas costumbres y defender, por vía sindical, la protección de sus derechos laborales. La revolución social requería que todos los trabajadores tuvieran un determinado nivel cultural, por ello había que incorporar a las mujeres a la gran tarea de la revolución. Sin embargo, al margen de una exigua minoría, las mujeres apenas entendieron la liberación ni se inquietaron por el rol que se le ofrecía en la construcción de la nueva sociedad. Tal vez debido a la inercia secular de no participación en los ámbitos culturales y laborales o por la natural resistencia a relegar la vida del hogar a un segundo plano.

A parte de las escuelas racionalistas el movimiento anarquista fundó Ateneos. Estos centros fueron impulsados por las federaciones locales de la CNT y desplegaron una intensa actividad cultural. Las organizaciones obreras para la difusión de la cultura y la instrucción escogieron los Ateneos que pervivieron con éxito hasta la guerra civil. El Ateneo libertario fue una de las instituciones que impulsaron los anarquistas; un centro multifuncional que era a la vez escuela, espacio recreativo y lugar de encuentro para los jóvenes de la clase obrera (Navarro, 2002). Marta Ackelsberg (1999, p. 67) refiere que fueron "lugar de encuentro y de intercambio cultural" donde se fomentaba el conocimiento y la instrucción sin exclusión. Allí se impartían clases diurnas para atender a los niños y nocturnas para los adultos, al tiempo que constituyeron una alternativa educativa para las mujeres. Al decir de la autora:

Los ateneos ofrecían oportunidades de preparación especialmente importantes para las mujeres de la clase obrera, que tenían a su alcance muchos menos espacios para tales experiencias que los hombres. Las mujeres que militarían luego en la CNT y/o en Mujeres Libres declararon de modo casi unánime que sus experiencias en ateneos, escuelas y actividades culturales habían sido cruciales en el proceso. Aprendieron a leer e, igualmente importante, a desarrollar relaciones plenas de sentido y valor con chicos de su misma edad, experiencia que les estaba vedada debido a la segregación casi total de sexos que se daba en la sociedad española. (Ackelsberg, 1999, p. 107)

Si bien ya funcionaban sociedades de extensión cultural de diversa filiación con anterioridad en la II República los Ateneos Libertarios se extendieron por toda el área de influencia anarquista (Sola, 1976). Aunque conjugaron los objetivos culturales y educativos con los emancipadores, especialmente durante el periodo republicano, se convirtieron en centros polivalentes que atendían las demandas educativas y de ocio de las clases trabajadoras (Navarro, 2003).

En ocasiones durante periodos de represión fueron lugares de propaganda y actividad sindical encubierta, como por ejemplo sucedió durante la dictadura de Primo de Rivera, cuando crearon grupos culturales, artísticos o naturistas ante la clausura de los locales sindicales. En suma la educación que pretendían los libertarios no se reducía a la infancia; su acción educativa también se proyectaba a los jóvenes y adultos de ambos sexos. Es 
decir que se orientaba a todo el pueblo, a los obreros, obreras, campesinos y campesinas. Prestaron la mayor atención a la enseñanza racional para lo cual era esencial un giro total al proceso educativo, potenciando una escuela para la libertad a la que asistieran conjuntamente ambos sexos. Para la España de la época donde la moral burguesa estaba muy arraigada era una iniciativa radical y peligrosa.

\section{La agrupación mujeres libres y su lucha por el cambio social}

Las mujeres anarcosindicalistas impulsaron una importante corriente educativa y cultural. Cabe destacar que en 1934 fundaron el Grupo Cultural Femenino en Barcelona. Estas pioneras atrajeron a sus filas a otras mujeres que poseían alguna formación académica. Las mujeres estaban integradas en el anarcosindicalismo y no existió ciertamente una rama específicamente femenina hasta 1936. Tampoco el movimiento libertario dispuso de una organización juvenil hasta 1932, porque la emancipación no hacía distingos de género ni de edades. No obstante, un nutrido grupo de mujeres del movimiento libertario de Madrid y Barcelona, rechazando parte de la gestión y de la organización anarcosindicalista, rompieron el modo de actuación y se incorporaron a la lucha feminista fundando el colectivo Mujeres Libres en 1936. Pretendían liberar a las mujeres de la "esclavitud de la ignorancia, esclavitud de mujer y esclavitud productora" (Mujeres Libres, 1936).

A pesar de su corta vida, pues desapareció en febrero de 1939 a raíz del éxito del ejército franquista, movilizó a miles de mujeres y desplegó un amplio programa de actividades siguiendo los principios anarcosindicalistas (Ackelsberg, 1999:23). Repetidamente Mujeres Libres denunciaban que las mujeres ocupaban un lugar subordinado en la sociedad y también en las propias organizaciones donde algunos militantes de la CNT no se interesaron por la participación femenina. La formulación del feminismo en base a la diferencia legitimó sus aspiraciones dentro del movimiento ácrata. Se trataba de un feminismo obrero, si bien no se identifican con el término y se hallaban distantes del feminismo burgués coincidían en los postulados (Nash, 2004).

Plantearon una enseñanza nueva para capacitar a las mujeres españolas de acuerdo a su realidad. Es decir para superar las elevadas tasas de analfabetismo, para prepararlas de forma activa y efectiva para su participación en las distintas esferas de la sociedad, y para "permitirles que adquirieran experiencia de sí mismas como actoras competentes en la historia" (Ackelsberg, 1999, p. 178).

Las mujeres más activas en el proceso de gestación de la agrupación fueron las provenientes del ambiente anarcosindicalista de Cataluña. En la fase de fundacional cabe recordar a Soledad Estorach, Pepita Carpena, Sara Berenguer, Azucena Fernández, Concha Liaño, María Jiménez, Pura Pérez, Suceso Portales y Antonia Fontanillas. En Madrid tres mujeres dinamizaron la organización. A saber la escritora Lucía Sánchez Saornil, la abogada Mercedes Comaposada y la médica Amparo Poch. El esfuerzo se tradujo en una organización que afiliaba a un colectivo estimado en más de veinte mil mujeres a finales de 1936, con particular presencia en Cataluña, Aragón y Valencia. Compartían la estrategia anarcosindicalista de capacitación y captación, como propuestas para modificar la situación femenina en España cuyo objetivo inicial era alentar a las mujeres a aproximarse al ideal libertario (Nash, 2004). 
En primer lugar pretendían ayudar a superar las carencias de instrucción formal de las mujeres obreras y campesinas, condición básica para poder incorporarse y participar activamente en el proceso de transformación social impulsado por el movimiento libertario español en las áreas donde tenía predominio (particularmente en Cataluña y Aragón). Realizaron una amplísima labor de capacitación educativa básica y aprendizaje laboral y organizaron jornadas de propaganda, bibliotecas móviles y eventos culturales dirigidas a las obreras y campesinas. Enfatizaban en las acciones de las mujeres, cuestionaban la vida privada y pedían que las faenas domésticas fueran compartidas. Por otra parte crearon una revista con idéntico rótulo Mujeres Libres, vocero que sintetizaba las ideas esenciales que impulsaron a este colectivo y cuyo primer número se editó en abril de 1936 (Montero, 2003). Cabe resaltar que la edición de la revista Mujeres Libres representaba el esfuerzo para entonces inédito de la creación femenina. Tanto los textos, como el diseño y componente gráfico llevaban rúbrica de mujeres. Completaban la tarea editorial con otras publicaciones periódicas, folletos, hojas de propaganda, afiches y libros.

El objetivo de Mujeres Libres era prepararlas para la revolución social, pero el estallido de la guerra las empujó de forma acelerada a evolucionar a un planteamiento feminista muy activo. Pero no se agotaron con la contienda nacional sus acciones, mantuvieron su dinámica y continuaron con la tarea de formación (Nash, 1975) ${ }^{7}$. La respuesta fue amplia y Mujeres Libres contaba a finales de 1936 con unas 20 mil mujeres repartidas entre 147 agrupaciones. Este colectivo desplegó una intensa labor y en menos de tres años de existencia llevaron a cabo diversas acciones. Crearon las academias para adultos con clases de alfabetización y cultura general, escuelas para niños, abrieron y gestionaron guarderías y comedores populares.

Los institutos de Mujeres Libres de Madrid, Barcelona y Valencia desplegaron una intensa actividad educativa y cultural. Atendían a la formación cultural y profesional de las mujeres con el objeto de capacitarlas para su participación activa en la sociedad. La oferta de instrucción para las obreras fue diversa, abarcando desde clases de alfabetización hasta la cualificación profesional. De manera que instruyeron a las mujeres en preparación básica para el acceso a los institutos obreros, enseñanzas de idiomas, cursos de puericultura, enfermería, corte y confección, comercio, electricidad, mecánica. Igualmente ofertaron un programa de conferencias semanales donde se disertaba de variada temática. En muchos lugares actuaron dentro de las iniciativas impulsadas por los sindicatos, mientras que en Barcelona desplegaron de modo independiente una actividad intensa y diversa. Allí abrieron el Casal de la Dona Treballadora, donde se atendieron entre 600 y 800 mujeres en clases de alfabetización, instrucción básica, mecánica y agricultura, sin olvidar descuidar los temas sindicales y económico-sociales. Al mismo tiempo crearon una Escuela de Enfermeras y el Instituto Materno-Infantil Louise Michel.

Entre las figuras claves en el anarcosindicalismo cabe mencionar a Mercedes Comaposada, Lucía Sánchez Saornil y Amparo Poch Gascón. Estas tres mujeres fueron muy conscientes de la prioridad educativa y de las necesidades de preparación del colectivo

\footnotetext{
${ }^{7}$ Entre sus objetivos pretendía: 1) "Preparar una poderosa aportación femenina a la tarea revolucionaria constructiva, ofreciendo a la misma enfermeras, profesoras, médicas, artistas, puericultoras, químicas, obreras inteligentes: algo más efectivo que la sola buena voluntad llena de ignorancia", y 2) "Combatir la ignorancia capacitando a las compañeras cultural y socialmente, por medio de clases elementales, conferencias, charlas, lecturas comentadas, proyecciones cinematográficos, etc." (Nash, 1975, p. 73-74).
} 
femenino. Desde sus coordenadas se comprometieron con la difusión de los conocimientos que consideraban básicos para todas las mujeres. La incultura de las trabajadoras marcadas por sus precarias condiciones de vida social y económica, las indujeron a emprender acciones formativas. Partían del lema instruir para avanzar, necesariamente había que alfabetizarlas, enseñarles postulados anarquistas y adiestrarlas para la vida libertaria. A todas les insistían en que la acción individual de cada mujer era fundamental para lograr el cambio social. Estos planteamientos fueron el germen de la mentada publicación Mujeres Libres, una revista mensual que no sólo cumplía como vehículo de difusión del ideario anarquista sino que cubría el objetivo de formación.

Los saberes populares irrumpían en las prácticas de la vida cotidiana y desde Mujeres Libres se pretendía romper las creencias tradicionales para erradicar tabús y supersticiones. En este orden, cabe resaltar a la actividad pedagógica de la médica Amparo Poch y Gascón, que preocupada por la ignorancia de las mujeres españolas, especialmente por el atraso y pobreza de los sectores populares, inculcó saberes de maternidad, puericultura, sexualidad e higiene (Rodrigo, 2002). Además de la actividad desplegada en su propio Consultorio Médico para mujeres y niños en Zaragoza y en Madrid, la labor divulgadora y formativa la canalizó a través de charlas y diversas publicaciones (Poch, 1931, 1932 y s/f)

En general el movimiento libertario se resistió a reconocer la especificidad y necesidad de autonomía en la lucha femenina. Por este motivo no quiso reconocer a la Agrupación Mujeres Libres como un organismo igual a las otras ramas del anarquismo (CNT, FAl y Juventudes) aunque partían de la unidad ${ }^{8}$. Este hecho constituye una muestra de la opresiva tradición del dominio de género. Esta actitud representaba la fuerza del imaginario sexista presente en la España de entonces, que observaba como algo secundario la problemática femenina. Fuera del ámbito ácrata eran vistas como parte de la "locura anarquista", que luego se usaría para justificar su desdén.

De igual manera el movimiento juvenil ácrata proyectaba los principios anarquistas para captar a las nuevas generaciones, sin descuidar la educación y cultura. Su difusión que alcanzó a las áreas urbanas pero también se acercaron a las zonas rurales, con la intención de alejar al campesinado de la ignorancia y despertar la conciencia ácrata (Tiana, 1987). Las Juventudes Libertarias constituyen, dentro del movimiento libertario español, la tercera agrupación por orden de creación. Brindó oportunidades a mujeres y hombres jóvenes, abrió expectativas y la posibilidad de contribuir en tareas sociales. Su lema se condensaba en la enseñanza libre para formar mujeres y hombres libres por medio de la enseñanza racional. Crearon escuelas racionalistas para atender la educación infantil y academias para adultos, que impartieron clases de alfabetización o cultura general (Tiana, 1987).

En 1932 se aglutinaron en la Federación Ibérica de Juventudes Libertarias. El objetivo de las Juventudes Libertarias era la agrupación de los jóvenes de ambos sexos para prepararlos para la revolución y educarlos para iniciar la lucha. Pretendían luchar por la libertad a través de todos los medios a su alcance, tales como periódicos, folletos, revistas, conferencias, charlas o bien de sus enseñanzas. Igualmente trataban de formar a los nuevos pensadores. Destacaron por su dinamismo y había un número importante de agrupaciones

\footnotetext{
${ }^{8}$ La revista Mujeres Libres (1936) lo expresa claramente: "No luchamos contra los hombres, No pretendemos sustituir el dominio masculino por el femenino. Es necesario trabajar y luchar juntos pues si no nunca tendremos la revolución social. Pero necesitamos nuestra propia organización para luchar por nosotras mismas" (Cfr. Por Liaño, 1999, p. 18).
} 
por buena parte de España, si bien tenían mayor influencia en la zona republicana a partir de 1936 y mantenían vínculos estrechos con la CNT y la FAl.

En Cataluña se consideraba una Sección de la FAI. Pero en otros lugares actuaron de forma independiente y mantuvieron una actividad autónoma. En ambos casos emprendieron acciones culturales diversas - excursiones, visitas, representaciones artísticas, concursos, conferencias, charlas, cursos de alfabetización, fomento de la lectura, creación de bibliotecas - en las que combinaban la instrucción con el proselitismo.

\section{Consideraciones finales}

Las propuestas educativas desarrolladas por el movimiento anarcosindicalista español constituyen una de las experiencias más importantes a nivel mundial. La educación y la cultura como instrumento para la liberación de las clases trabajadoras fue una de las máximas del anarquismo y a las que prestó atención constante. Conjugaron los planteamientos propagandísticos y emancipadores con los formativos. En su posición política confluyó la concepción militante de la educación y la cultura de carácter no formal con la finalidad emancipadora. El objetivo de transformar los valores y fomentar la cultura popular para cambiar el rumbo social implicaba renovarse frente al modelo educativo tradicional y los rancios convencionalismos.

Por ello, siguiendo su discurso ideológico, el movimiento libertario desarrolló un conjunto de actividades de educación no formal para hombres y mujeres. El entusiasmo se proyectaba como un apostolado y difundían la doctrina para lograr su objetivo de instruirse para avanzar. Predicaban en pueblos y ciudades insistiendo en la ilustración para conseguir la emancipación. En la concreción de su programa insistían en la liberación, emancipación y redención conjunta de mujeres y hombres. Porque la movilización femenina junto a la masculina permitía alcanzar los propósitos de transformación social y de construir la sociedad alternativa soñada.

La educación femenina tenía como mira el desarrollo cultural de las mujeres, en cuanto que su incorporación activa a la sociedad era fundamental para la construcción de un nuevo orden y en base a ello defendían su derecho a escolarizarse. Los anarquistas necesitaban a las mujeres como compañeras y colaboradoras, por lo cual había que alejarlas de la superstición y la ignorancia integrándolas en su proyecto común. Las mujeres estaban presentes en sus reivindicaciones y su liberación era una constante en su lucha. Se hallaban integradas en los grupos ácratas y tenían una presencia notada en las organizaciones obreras porque eran necesarias. La emancipación afectaba al ámbito público y privado, en una sociedad antiautoritaria y antijerárquica pero consideraban que el feminismo estaba vinculado a la burguesía.

Realmente hasta 1936 con la creación de Mujeres Libres, fundada en Madrid bajo el signo del feminismo libertario, no existió una rama específicamente femenina. Se significaban como revolucionarias, reivindicaban un espacio social, político y laboral para las mujeres en una sociedad nueva; sus planteamientos no confluían en los postulados de las burguesas y se hallaban distantes del feminismo burgués. El grupo femenino incidió en su actuación para potenciar la actividad de las mujeres y no ir a remolque de los hombres. Ellas incidían en la necesidad de actuar de forma independiente y romper con la subordinación de los hombres. Mantenían los principios anarcosindicalistas, pero incorporaron sus valores y problemas buscando alternativas. Sin embargo, la actuación del movimiento libertario 
estuvo marcada por el sesgo de género, se resistieron a reconocer la especificidad femenina porque no lograron desprenderse de los atavismos.

El imaginario ácrata también se reflejó en el espejo de la sociedad sexista española. Pese a sus avanzados planteamientos no se desprendió de los estereotipos ni rompió con el modelo tradicional y las creencias discriminatorias de la época. Muchas experiencias realizadas durante el trienio bélico (1936-1939), especialmente en Cataluña, pusieron de relieve el esfuerzo por extender la educación ácrata y superar el carácter marginal. Si bien el principio de neutralidad ideológica se vio ensombrecido ya que utilizaron la educación como causa revolucionaria.

El levantamiento armado y el consiguiente triunfo del gobierno militar tras la cruenta guerra civil, aniquiló los vestigios democráticos y autogestionarios. Con la dictadura se desarticuló al movimiento obrero, se encarceló, persiguió y reprimió todo aquello que refería a libertades y derechos. Desarticulados y acéfalos pasó a la clandestinidad y muchos tomaron el camino de la expatriación. Toda la fulgurante actividad del grupo femenino Mujeres Libres igual que toda la actividad de los anarquistas se vio truncada por el triunfo de las fuerzas del general Franco. La dictadura militar condujo a estas mujeres a la cárcel, al exilio, a volver a la situación contra la que se habían rebelado, o lo que tal vez fue peor al silencio que negaba a muchas mencionar la experiencia más rica de sus vidas.

Desmemoriadas y olvidadas en la sombra de la historia tuvieron que adoptar múltiples estrategias y sortear barreras de obstáculos para sobrevivir. El exilio significó desesperanza y debilitamiento del movimiento ácrata, afectando igualmente a las integrantes de Mujeres Libres, a quienes ni siquiera les fue posible mantener un mínimo de continuidad como grupo ni con los pocos efectivos del anarquismo. Décadas más tarde varios colectivos españoles retomaron su nombre y en la actualidad funcionan también otros grupos en Francia, Colombia, Argentina y España.

Para terminar resta decir que los anarquistas desde la centuria decimonónica planteaban la igualdad y en su trayectoria desarrollaron diversas acciones encaminadas a tal fin. Sin embargo, ha sido a comienzos del siglo 21 cuando los gobiernos españoles se han comprometido y apostado por la igualdad entre sexos. De ahí que hayan planteado la importancia y la necesidad de establecer la igualdad entre hombres y mujeres. Resultado de esta acción ha sido la entrada en vigor la Ley Orgánica de Igualdad bajo gobierno socialista.

En los últimos veinticinco años las mujeres españolas han protagonizado el mayor avance social de su historia. Han experimentado un cambio revolucionario frente a las décadas anteriores, si bien persisten viejas rémoras. Su historia nos ha permitido conocer muchos aspectos ignotos del pasado a través de una mirada en femenino, desde una perspectiva más amplia y divergente focalizada en las protagonistas marginadas por la tradición. 


\section{Referencias}

ACKELSBERG, Martha. Mujeres libres: el anarquismo y la lucha por la emancipación de las mujeres. Barcelona: Virus, 1999.

ALVAREZ JUNCO, José. La ideología política del anarquismo español (1868-1910). Madrid: Siglo 21, 1976.

BALLARIN DOMINGO, Pilar. La educación de las mujeres en la España contemporánea (siglos 19 y 20). Madrid: Síntesis, 2001.

CABALLERO, Fermín. Sobre la educación mixta de los niños de ambos sexos, en Memorias de la Real Academia de Ciencias Morales y Políticas. Tomo IV. Madrid: Topografía Gutemberg, 1883, p. 399-402.

ESPIGADO, Gloria. Las mujeres en el anarquismo español (1869-1939). Revista Ayer, $\mathrm{n}$. 45, 2002, p. 39-72.

ESPIGADO, Gloria. Mujeres radicales: utópicas, republicanas e internacionalistas en España (1848-1874). Revista Ayer, n. 60, 2005, p. 5-43.

GARCÍA MOROTO, Maria Ángeles. La mujer en la prensa anarquista, España 1900-1936. Madrid: Fundación de Estudios Libertarios Anselmo Lorenzo, 1996.

GUEREÑA, Jean Louis. European influences in spanish popular education: the case of the socialist Casa del Pueblo of Madrid and the belgian model (1897-1929). History of Education, London, n. 35, 2006, p. 29-37.

JAGOE, Catherine. La enseñanza femenina en la España decimonónica. En: JAGOE, Catherine; BLANCO, Alda; ENRIQUEZ, Cristina. La mujer en los discursos de género. Barcelona: Icaria, 1998, p. 105-145.

LIAÑO, Concha. Mujeres Libres: luchadoras libertarias. Madrid: Fundación de Estudios Libertarios Anselmo Lorenzo, 1999.

LITVAK, Lily. El cuento anarquista (1880-1911). Madrid: Fundación de Estudios Libertarios Anselmo Lorenzo, 2003.

LITVAK, Lily. Musa libertaria: arte, literatura y vida cultural del anarquismo español (18801913). Madrid: Fundación de Estudios Libertarios Anselmo Lorenzo, 2001.

LOPEZ SANTAMARIA, Jesús. Despensa para las mujeres, dispensa para los hombres. La presencia de género en el anarquismo hispano. En: CUESTA BUSTILLO, Josefina (coord.). Historia de las mujeres en España: siglo 20. V. 1. Madrid: Instituto de la Mujer, 2003, p. 405412.

LORENZO, Anselmo. Contra la ignorancia. Barcelona: Imp. I. Ortega, s/f.

LORENZO, Anselmo. El proletariado militante. Madrid: Alianza, 1974.

LUIS, Francisco de. Cincuenta años de cultura obrera en España (1890-1940). Madrid: Pablo Iglesias, 1994.

MELLA, Ricardo. Cuestiones de enseñanza libertaria. Madrid: Zero-Zyx, 1979.

MONTERO BARRADO, J.M. Anarcofeminismo en España: la revista Mujeres Libres antes de la guerra civil. Madrid: Fundación de Estudios Libertarios Anselmo Lorenzo, 2003. 
NASH, Mary. Mujeres en el mundo: historia, retos y movimientos. Madrid: Alianza, 2004 NASH, Mary. Mujeres libres: España 1936-1939. Barcelona: Tusquets, 1975.

NAVARRO NAVARRO, Francisco Javier. Ateneos y grupos ácratas: vida y actividad cultural de las asociaciones anarquistas valencianas durante la segunda república y la guerra civil. Valencia: Generalitat Valenciana, 2002.

NAVARRO NAVARRO, Francisco Javier. Mundo obrero, cultura y asociacionismo: algunas reflexiones sobre modelos y pervivencias formales. Hispania: Revista Española de Historia, Madrid, v. 63, n. 214, 2003, p. 467-484.

POCH Y GASCÓN, Amparo. Cartilla de consejos a las madres. Zaragoza: Junta de Protección a la Infancia y Represión de la Mendicidad, 1931.

POCH Y GASCÓN, Amparo. Niño: artículos de puericultura. Revista Mujeres Libres, Madrid, folletos monográficos, s/f.

POCH Y GASCÓN, Amparo. La vida sexual de la mujer: pubertad-noviazgo-matrimonio. Valencia: Cuadernos de Cultura, LV, Tip. P. Quiles, 1932.

PUELLES BENITEZ, Manuel. Historia de la educación en España: de las Cortes de Cádiz a la Revolución de 1866. Madrid: MEC, 1985.

RODRIGO, Antonina. Una mujer libre: Amparo Poch y Gascón, médica y anarquista. Barcelona: Flor del Viento, 2002.

TAVERA GARCÍA, Susana. Mujeres que rompieron moldes. Clío: Revista de Historia, Madrid, n. 10, 2002, p. 18-19.

TIANA FERRER, Alejandro. Educación libertaria y revolución social. Madrid: Uned, 1987.

TIANA FERRER, Alejandro. Los movimientos obreros y la educación. En: DELGADO CRIADO, Buenaventura. Historia de la educación en España América. Madrid: Morata, 1994, p. 600-604.

TIANA FERRER, Alejandro. La idea de enseñanza integral en el movimiento obrero internacionalista español (1868-1881). Historia de la Educación, n. 2, 1983, p. 113-123.

TIANA FERRER, Alejandro. El modelo educativo del movimiento obrero. En: TIANA FERRER, Alejandro; SANZ, Florentini. Génesis y situación de la educación social en Europa. Madrid: Uned, 2003, p. 175-201.

SCANLON, Geraldine. La polémica feminista en la España contemporánea (1868-1974). Madrid: Akal, 1986.

SCANLON, Geraldine. La mujer y la instrucción pública: de la ley Moyano a la II República. Historia de la Educación, n. 6, 1987, 193-207.

SOLA, Pére. Los ateneos obreros y su función educadora: de la Restauración a la II República. Cuadernos de Pedagogía, n. 16, 1976, p. 30-31.

TERESA GONZÁLEZ PÉREZ é profesora titular de Historia de la Educación, área de Teoría e Historia de la Educación del Dep. Historia y Filosofía de la Ciencia, la Educación y el Lenguaje - Universidad de La Laguna (Tenerife - Islas Canarias España). Doctora en Historia, maestra, licenciada en Historia, licenciada en Filosofía y Ciencias de la Educación. Imparte docencia en la Facultad de Educación, en los grados de Pedagogía y Maestro. 
Contacto: Universidad de La Laguna - Dep. Historia y Filosofía de la Ciencia, la Educación y el Lenguaje - Edificio Central, 1ạ planta - Avda. Trinidad, s/n - 38204 San Cristóbal de La Laguna - Tenerife - España.

E-mail: teregonz@ull.es.

Recebido em 11 de maio de 2012.

Aceito em 19 de novembro de 2012. 